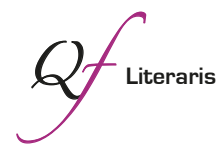

\title{
Lena Constante. Experiencia carcelaria y búsqueda de la palabra liberadora en lengua francesa
}

\author{
Margarita Alfaro Amieiro \\ Universidad Autónoma de Madrid \\ margarita.alfaro@uam.es
}

\begin{abstract}
Resumen: Lena Constante (1909-2005), escritora de origen rumano, elige la lengua francesa para escribir su testimonio en las cárceles rumanas entre 1950 y 1957. Su vivencia, en un contexto de opresión totalitaria y de injusta acusación, expresa de modo somero las condiciones políticas en las que se produjeron los acontecimientos. Ahora bien, la autora desarrolla todo un conjunto de estrategias transgresoras, ligadas a la composición verbal que plasma en su obra autobiográfica L'évasion silencieuse. Trois mille jours seule dans les prisons roumaines (1990). Lejos de alcanzar la felicidad, realiza su propio camino de liberación interior frente al silencio, el aislamiento y las torturas impuestas. Palabras clave: Lena Constante; cárcel; silencio; escritura; francés; transgresión-liberación.
\end{abstract}

\section{Lena Constante. Experience of imprisonment and quest for the word of freedom}

Abstract: Lena Constante (1909-2005), writer of Romanian origin choose the French language to write her testimony in Romanian prisons between 1950 and 1957. Her experience, in a context of totalitarian oppression and unjust accusation, express in a cursory manner the political conditions in which the events occurred. However, the author develops a set of transgressive strategies linked to the verbal composition reflected in her autobiographical work $L$ 'évasion silencieuse. Mille trois jours seule dans les prisons roumaines (1990). Far from achieving happiness, makes her inner journey against the silence, the isolation and the imposed tortures.

Keywords: Lena Constante; jail; silence; writing; French; transgression; release. 



\section{Presentación}

Desde la óptica de la escritura carcelaria, Francia y la lengua francesa se han convertido a lo largo del siglo XX en una tierra de acogida para ciudadanos y escritores originarios de la Europa del Este, en especial durante el periodo totalitario inspirado en el modelo estalinista (Porra, 2011). El caso de Rumanía es singular, son muchos los escritores y escritoras que han adoptado el francés como lengua de creación desde el inicio del siglo XX hasta el umbral del siglo XXI. Recordemos los ejemplos significativos de Hélène Vacaresco (1866-1947), Anne de Noailles (1876-1933) y Marthe Bibesco (1888-1973), exiliadas en Francia a inicios de los años 40 a causa del impulso fascista.

Con posterioridad, observamos la presencia de otras escritoras que eligen el exilio en Francia durante la década de los años 80: Oana Orlea (1936-2014) y Rodica Iulian (1931-) (Steiciuc, 2010: 139-147), entre otras más. Todas ellas ilustran una nueva dimensión literaria, caracterizada por el compromiso de describir el horror o les tropismes de l'horrible (Camboulives, 2005: 57).

Lena Constante (1909-2005), perteneciente a la misma generación y formada en el ámbito de las Bellas Artes, escribe con anterioridad a Oana Orlea, conocida en Francia por su relato autobiográfico titulado Les années volées. Dans le goulag roumain à seize ans (1992)1. Constante representa, sin embargo, una voz menos conocida del exilio en lengua francesa por medio de la cual tematiza su experiencia en las cárceles rumanas en torno a la descripción de la tortura ${ }^{2}$. Lena Constante, dos años antes que Oana Orlea, publica L'évasion silencieuse. Trois

\footnotetext{
* Este artículo se inscribe en el marco de los objetivos de investigación del proyecto de I+D + i FFI2013-43483-R.

${ }^{1}$ Oana Orlea se exilia en Francia en 1980 a consecuencia de su enfrentamiento con el sistema totalitario en Rumanía desde la edad de los 16 años. Durante dos años, entre 1952-1954, estuvo en prisión y después de su exilio escribe en lengua francesa el testimonio de su pasado. Tanto su obra de ficción, Une sosie en cavale (1986), como su autobiografía abordan la tragedia bajo el yugo totalitario (Alfaro, 2012: 678-681).

${ }^{2}$ Cabe establecer un paralelismo entre Lena Constante, a la que nos referiremos, y Margarete Buber-Neumann (1901-1989), quien estuvo como prisionera, primero, en la Unión Soviética (1937-1940) y, después, en la Alemania nazi. En su obra Bajo dos dictadores: Prisionera de Stalin y Hitler (1948) relata su doble experiencia carcelaria.
} 
mille jours seule dans les prisons roumaines (1990)³. Así pues, Constante escribe más de treinta años después de quedar en libertad en su tierra natal y haber dedicado mucho tiempo a escribir sus recuerdos sin el objetivo de sacarlos a la luz debido a la situación de falta de libertad en Rumanía:

La Roumanie des années 1950-1960 a connu l'horreur des prisons politiques, les camps de travail et les déportations en résidence assignée, autant de modalités pour le nouveau régime de se débarrasser des anciens leaders politiques, des intellectuels ou des artistes qui refusaient de "signer le pacte" (Steiciuc, 2010: 139).

Constante empieza a escribir el manuscrito, primero en un viaje a París en 1977, y con posterioridad durante los diferentes viajes al extranjero. Ello le permitió transcribir las notas recopiladas después de haber salido de la cárcel, sin que tuvieran una dimensión política que supusieran para ella una situación comprometida. En 1985, durante un nuevo viaje a París, toma contacto con dos compatriotas rumanas exiliadas que impulsan la edición y su publicación. Constante, muy arraigada en la tradición y el conocimiento del folklore de los campesinos rumanos, no elige el exilio de su territorio a pesar de las duras condiciones en las que tuvo que vivir después de su liberación. La lengua francesa se convierte así, en un primer momento, en su terre d'accueil (Delbart, 2005: 52-55). Nuestra autora ilustra de manera singular la noción de exilio lingüístico, la lengua le permite tomar distancia de su experiencia trágica y experimentar la libertad añorada (Constante, 1990: 297).

Así pues, su obra, de naturaleza autobiográfica, escrita en francés y publicada en Francia, expresa no solo lo vivido desde la descripción que busca la verosimilitud y el detalle minucioso escudriñado en el recuer-

\footnotetext{
${ }^{3}$ La autora traduce la obra al rumano en 1992 bajo el título de Evadarea tăcută, en 1995 verá la luz la segunda edición. La versión francesa recibe en 1992 el Prix Européen y el Premio de la Association des Ecrivains de Langue Française. En 1994 recibe el galardón Lucian Blaga de la Academia Rumana. En 1999 recibe el Prix pour un destin exceptionnel dans la culture roumaine de la Fundación Cultural Rumana. Constante en 1993 escribe en rumano un segundo libro titulado Evadarea imposibilă, la Evasión imposible, en el que describe desde otro prisma la detención comunista (Geambei, 2013: 143-152). Los dos libros de Constante han tenido una buena recepción en Rumanía y, además de la versión francesa de su primer libro, su obra ha sido traducida al inglés y publicada con éxito en Inglaterra y Estados Unidos.
} 
do, sino que introduce estrategias diversas para transcender la experiencia personal en otra lengua diferente a la propia (Constante, 1990: 290). El contexto histórico de los acontecimientos que el pueblo rumano vive bajo el régimen comunista de Gheorghiu-Dej (1949-1965) ${ }^{4}$ es somero, no se trata del objetivo principal de la autora. Si bien es preciso, el lector tiene acceso a los elementos más relevantes que permiten conocer el contexto general: la imposición de la URSS en Rumanía, el exilio del rey Miguel I y un gran número de arrestos arbitrarios con la finalidad de imponer un gobierno comunista bajo el régimen del miedo que se concreta con el establecimiento de la República Popular de Rumanía. Además, en el plano artístico, se instala una estricta censura política que tiene graves repercusiones sobre el ámbito de la literatura entre los años 1945-1989. Muchos escritores son proscritos, la selección de lecturas se hace muy limitada y los temas son depurados. Esto explica que a partir de 1989, debido a las prohibiciones anteriores, surja con fuerza la literatura de memorias y la literatura autobiográfica sin que medien procedimientos retóricos destinados al disimulo (Lazăr, 2013).

La autora voluntariamente se aleja lo más posible de los detalles políticos e introduce un relato introspectivo en primera persona que evoca su condena a doce años de prisión en un momento de madurez personal donde lo más relevante es su capacidad interior frente a las agresiones del exterior, para no perder su dignidad y fortalecer el exilio interior, $l a$ evasión silenciosa. La primera persona alterna en muchos momentos con la tercera persona y ello le permite mostrar la distancia que ella misma toma ante las difíciles situaciones que se le imponen.

Desde el punto de vista formal la obra está articulada en tres partes, que se corresponden parcialmente con la evolución cronológica del tiempo pasado en prisión. Ello se debe a que se produce un paréntesis en la segunda parte, en la que hay una mirada retrospectiva para plantear los antecedentes previos al tiempo de la prisión, y las circunstancias azarosas que dieron lugar al proceso de la justicia que la consideró culpable. La consecuencia para ella fue la de obtener la condición de prisionera política durante todo el tiempo de su condena. Este estatus suponía un trato mucho más duro en la cárcel así como el aislamiento total.

\footnotetext{
${ }^{4}$ Dirigente político y secretario general del PCR (1944-1965), consigue durante el tiempo de su mandato mantener progresivamente la distancia con la Unión Soviética hasta conseguir la salida de las tropas del Ejército Rojo en 1958 y alcanzar una cierta independencia económica. No obstante se mantuvo fiel al Pacto de Varsovia.
} 
Ruxandra Cesereanu (2005) ha analizado diferentes ejemplos de escritura concentracionaria comunista y clasifica la obra de Lena Constante de escritura no ficcional. La estrategia temporal es asimismo muy significativa, distingue entre el tiempo evocado (el presente de la detención y los hechos que acaecen) y el tiempo de la evocación (el tiempo del recuerdo) y califica su obra en lengua francesa de diario postdetención ya que Constante se supedita, debido a la perspectiva histórica, al relato del tiempo cronológico y se sirve del tiempo presente. Por el contrario, si el relato hubiera sido escrito en el momento de los hechos, la escritura hubiera estado condicionada por el sufrimiento de la tortura y por lo tanto por la vivencia de lo inmediato y hubiera perdido la capacidad estético-ética que se muestra. En este sentido Cesereanu considera que la elección temporal así como las estrategias lingüísticas que ofrece la obra favorecen más la dimensión literaria y estilística que la dimensión historiográfica, que se presenta como secundaria.

La primera parte abarca entre enero de 1950 y abril de 1954, tiempo durante el cual recorrió cuatro cárceles diferentes; fue encarcelada el 17 de enero de 1950. La segunda parte, más breve que la anterior, narra los acontecimientos entre abril y octubre de 1948 que supusieron de manera inesperada su condena y la de su amigo y futuro esposo, el reconocido etnólogo y folklorista, Harry Brauner ${ }^{5}$ debido a haber conocido circunstancialmente al jefe del Partido Comunista, Pătrăşcanu ${ }^{6}$ y a su esposa, quienes también fueron condenados. Y la tercera parte desarrolla las experiencias vividas en los dos centros penitenciarios en los que estuvo antes de volver a recuperar la libertad el 1 de octubre de 1957: Dumbraveni y Miercurea-Ciuc en la región de Transilvania.

\footnotetext{
${ }^{5}$ Harry Brauner conseguirá también salir de la cárcel tras los doce años de condena, después estuvo bajo supervisión alejado de Bucarest. A pesar de la separación pudieron casarse en condiciones muy precarias y tiempo después llevar a cabo una vida en común en Bucarest. En 1968 Lena Constante y Harry, bajo el régimen de Ceauceşcu, fueron de nuevo juzgados y considerados inocentes por el Tribunal Militar.

${ }^{6}$ Miembro del partido comunista rumano y ministro de Justicia, es acusado falsamente de espionaje y detenido en 1948 debido a su posición crítica contra el dogmatismo estalinista. Durante dos años estuvo bajo vigilancia cerca de Bucarest y encarcelado en 1950 junto a su esposa. El proceso supuso el arresto de otras personas vinculadas al mundo de la cultura que coinciden con él en una representación de marionetas animada por su esposa, entre las que estaba Lena Constante y Harry Brauner. En 1954 tuvo lugar el proceso con ciento cincuenta falsos testigos. El tribunal condenó a muerte a Pătrăşcanu y fue ejecutado de inmediato en la prisión de Jilava.
} 
En el último capítulo observamos la presencia en cursiva de dos testimonios de la propia autora que muestran la presencia del tiempo de la evocación como una necesidad para justificar su voluntad de escribir en un momento donde todavía puede recibir represalias. En el primer testimonio apuesta por la libertad de expresión así como por la función terapéutica y catártica de la escritura para ella misma (Constante, 1990: 250). Y en el segundo testimonio hay una referencia al estado en el que se encuentran tanto su amigo y futuro esposo como ella en los dos momentos temporales, el del pasado al que se refieren los acontecimientos, y en el presente cuando el estado de salud es precario a causa de los tormentos físicos y morales vividos. En la confluencia de ambos tiempos se impone la ensoñación de la pesadilla: "Concentre-toi! Rappelle-toi! Retourne dans ton enfer! Porte de nouveau ton fardeau ... Les douleurs et la faim" (Constante, 1990: 254).

Además, el conjunto del relato está acompañado por dos elementos paratextuales muy pertinentes para entender el valor inherente del texto: una breve presentación y un postfacio más rico en detalles que la presentación. La presentación plantea de manera desgarradora el drama de la mujer adulta, en el momento de su detención tenía 41 años, ante el miedo físico y psicológico y la soledad absoluta en un contexto hostil. El tiempo presente utilizado, como si se tratara de un diario íntimo en el que confluyen el tiempo de la escritura y el momento de los hechos, intensifica el sentido de verosimilitud y autenticidad (Constante, 1990: 5).

Los 12 años iniciales se vieron reducidos a 7 años debido a su situación muy delicada de salud y a las circunstancias políticas de distanciamiento con la Unión Soviética. Sabemos en la tercera parte del relato que tuvo una tuberculosis en estado muy avanzado que le impedía mantenerse en pie. Asimismo, anuncia, por una parte, las consecuencias psíquicas y psicológicas de la detención: "Le choc de ces sept années de détention fait éclater mon cerveau en miettes. Je ne ressens plus rien" (Constante, 1990: 5). Y, por otra parte, describe las condiciones materiales a las que se enfrenta:

Ils m'apportent chaque jour, midi et soir, une écuelle d'un liquide noirâtre et une mince tranche de pain. Je ne peux pas les avaler. Je ne peux même pas les voir. Mes yeux sont fermés. Sous mes paupières, du noir. Je ne sens plus mes bras. Je ne sens plus mes jambes. Je me dissous (Constante, 1990: 5-6). 
El postfacio plantea la génesis de la escritura y abunda en las condiciones políticas en Rumanía desde 1944 hasta el momento de la escritura para poder contextualizar el tiempo vivido en prisión. Ante todo lo vivido, la escritura está ligada a la necesidad de creación artística y de refugio en la imaginación como vías de salvación, como elementos para una nueva epifanía personal al margen de la identidad impuesta por el Estado a los individuos. Así pues, Lena Constante, ante su propia decisión de escribir antes de la caída del muro de Berlín, asume las posibles represalias ejercidas por el poder del Estado ya que se reafirma en expresar que su capacidad de libertad está anclada en su interior:

C'est à Paris, en 1977, que j'ai commencé à écrire ce livre et ce travail dura assez longtemps.

À Bucarest, je n'avais pas beaucoup de temps libre. [...] J'ai donc écrit pendant mes voyages à l'étranger. Je transcrivais chaque fois ce que j'étais parvenue à écrire en caractères microscopiques sur un cahier, à feuilles très fines. Pour pouvoir cacher plus facilement mon manuscrit. Mes Mémoires ne sont pas un texte politique. [...] Après sa publication, nous aurions eu à supporter à Bucarest les plus graves conséquences. Donc, choisir la liberté? (Constante, 1990: 297).

Una vez en la cárcel se ve enfrentada a la humillación física y moral, no obstante supo experimentar la libertad interior desde lo más profundo de su ser tras un proceso de autoconocimiento. Después de abandonar la prisión, a pesar de las todavía duras condiciones políticas, se sintió libre en Rumanía debido a la fidelidad y admiración que sentía hacia sus gentes y su lengua; esta dimensión se ve reforzada por el apoyo incondicional y cualificado de Harry, su esposo, como conocedor de excepción del folklore y la riqueza lingüística de la lengua rumana. Por último, el hecho de escribir en lengua francesa, su cauce instrumental, hizo posible el milagro de legar un testimonio que, más allá de un caso en particular, quiere ser la voz interior que representa a toda una colectividad:

À celui qui n'a pas subi, jour après jour, pendant des années, l'humiliation, l'esclavage, les rancœurs refoulées, l'impuissant désir permanent de vengeance, le froid, la malnutrition, le manque total d'horizon, il sera impossible de nous comprendre tout à fait.

Ce livre n'est pas l'histoire d'un cas isolé. Nous ne fûmes pas seuls à souffrir. La grande masse du peuple roumain fut écrasée sous le poids 
d'un régime inhumain et aberrant et des centaines de milliers de Roumains subirent de lourdes années de prison. [...] J'espère que nul lecteur de ce livre ne pourra croire que c'est un titre de gloire (Constante, 1990: 298).

La autora, al inicio del relato, se refiere de modo explícito a las razones que la han impulsado a escribir: aportar un testimonio humano dejando de lado, casi por completo, la parte política; expresar la dignidad humana, en especial de las mujeres que fueron sus compañeras en las dos últimas prisiones y a las que rinde un homenaje por su capacidad de solidaridad entre ellas; y, por último, expresar la esperanza de construir un mundo más justo (Constante, 1990: 21).

Lena Constante se convierte por tanto, a través de su relato autobiográfico, en una heroína del aquí y el ahora sin excesivas pretensiones de protagonismo. Asimismo, ofrece al lector occidental la evolución de su devenir existencial donde se reflejan los conflictos internos y su modo de relacionarse con su entorno, los verdugos y los representantes de la justicia de un sistema opresor a los que trata sin excesiva carga de acusación. Todos ellos están despojados de sus nombres para marcar más la distancia y crear un efecto de disolución de sus funciones otorgadas por un sistema fundamentado en el miedo y sin posibilidad de introducir ninguna oposición, esencia de la dominación totalitaria según la tesis desarrollada por Hannah Arendt en su obra Los orígenes del totalitarismo (1951).

En este marco, iremos descubriendo, a medida que avanza el hilo anecdótico, a un personaje que se derrumba y se fortalece hasta convertirse en portavoz de una dimensión histórica cargada de verosimilitud. La autora no persigue legar un testimonio documental meramente personal sino dejar el documento del alma (Geambei, 2013: 148). La dimensión autobiográfica del relato de los hechos, todo lo referido a la detención injusta, queda en un plano secundario y la autora otorga más protagonismo al análisis interior, al flujo de una conciencia que se interroga y se debate en contradicciones personales.

\section{Crónica de la evasión}

Hechas estas consideraciones, focalizaremos nuestra reflexión en un aspecto significativo de orden temático, inherente a la evolución interior de la voz autorial. Se trata del movimiento de construcción de la 
fortaleza interior, de la constitución de un sentir superior y de las estrategias de evasión ligadas existencialmente a la creación escriptural. Dicho movimiento proviene de la parte descriptiva del texto por medio de la cual el lector conoce los antecedentes de la acusación y la encuesta judicial. Todos los avatares que vive la autora con los verdugos, provocados por un sistema político represivo, darán lugar a la experiencia de la tortura y a la acusación injusta. Constante ha sido víctima de una situación de injusticia y de falsas acusaciones en un contexto político donde los individuos se encuentran desprotegidos ante las imposiciones del Estado. Siente que ha sido une comparse, une utilité (Constante, 1990: 20). Así se expresa la autora al inicio del relato, observamos el procedimiento anafórico de repetición y el ritmo ágil y sonoro del verso libre, en relación al sentido que cobra el acto de escritura en su vivencia existencial:

Enfin écrire pour protester.

Contre le pouvoir absolu.

Contre le contrôle de la pensée.

Contre la détention arbitraire.

Contre la détention comme moyen de vaincre la liberté de pensée.

Contre le pouvoir absolu de l'enquête et des enquêteurs.

Contre la détention comme instrument de punition avant toute condamnation.

Contre la torture.

Contre l'isolement complet.

Pour demander la justice des hommes pour les hommes.

Pour demander la pitié des hommes pour les hommes (Constante, 1990: 22).

Las estrategias de evasión se hacen presentes desde los primeros días de estar en la cárcel, surgen como consecuencia del sentimiento de indignación y rebeldía que experimenta la autora debido a las injusticias físicas y morales a las que se tiene que enfrentar. Ante la presencia reiterada de la acusación injusta, los múltiples interrogatorios y los castigos impuestos por el sistema represor surge el sentimiento de una fortaleza casi irracional por ser inusual (Constante, 1990: 13).

Desde el inicio Constante entiende que solo mediante el proceso de tomar conciencia de su situación puede sobrevivir. Así pues, todas las destrezas desarrolladas por la autora son muy variadas a lo largo de 
toda su estancia en la cárcel. Se trata de potenciar recursos vinculados a su capacidad de imponerse una disciplina física que le permita fortalecerse ante el dolor así como para desarrollar herramientas vinculadas a la sensorialidad corporal y a la creación verbal, artística, pictórica e imaginativa. Asimismo, combate la tortura impuesta del maltrato físico para no expresar mediante sonidos el dolor que experimenta, ello hace que se sienta poco a poco más aguerrie (Constante, 1990: 29) 7 . Después se concentra en agudizar el oído y el olfato para saber en qué momento aparece su verdugo en la celda y evitar posibles represalias. No sin dificultades, convenciéndose a sí misma, nuestra autora alcanza un estado de estoicismo y de aceptación tanto de la rabia como de su insignificancia, que le permite no sucumbir ante el dolor y el miedo (Constante, 1990: 74).

Tras una primera toma de conciencia vinculada a lo material y sensorial, Lena entiende que la supremacía del espíritu puede transformar la percepción de la realidad. Constante empieza por hacer ejercicios para recordar versos rumanos, sobre todo se concentra en la poesía popular con la que estaba familiarizada. Poco a poco, sin disponer ni de papel ni de lápiz, descubre, como si fuera una revelación profética, que el ritmo y la entonación están fundamentados en el acento tónico de las palabras (Constante, 1990: 65). Poco después tiene la idea de poner música a sus versos y de experimentar por todo ello una cierta alegría que le permite transcender su miserable situación: "J'avais enfin trouvé la clé de l'évasion. [...] J'abolissais la prison. La peur. Moi-même" (Constante, 1990: 61-62).

Otra experiencia positiva fue la de la lectura, su verdugo le ofrece un libro de Gorki, La madre, y en los días sucesivos, de manera excepcional, tiene acceso a otros libros del mismo autor. Este primer contacto con la lectura le hace descubrir universos oscuros y sórdidos que no le satisfacen. Entre los libros que recibe descubre un tratado de prosodia de Maiakovski, que será su libro de referencia para conocer todos los rudimentos del ritmo y del arte de la composición: élaguer, renoncer, condenser (Constante, 1990: 63). Nuestra autora, en la etapa breve en

\footnotetext{
${ }^{7}$ Esta misma exigencia la encontramos en los personajes gemelos de la novela $\mathrm{Le}$ Grand cahier (1986) de Agota Kristof (1935-2011), escritora de origen húngaro exiliada en Suiza desde 1956 debido a la invasión soviética. El conjunto de su obra denuncia las consecuencias del totalitarismo en los individuos.
} 
la que pudo tener contacto con los libros y leer de manera intensiva, descubrió las palabras, su gran fuerza semántica así como la posibilidad de percibir el tiempo bajo otra dimensión y sentir la vida desde la experiencia épica: "Avec cet amalgame de mots et de temps, j'ai vécu. Survécu. J'ai réussi même à être heureuse ... Quelquefois ..." (Constante, 1990: 63). Constante penetra así en un cronotopos sutil y etéreo que adquiere progresivamente una dimensión salvífica, a diferencia de la topografía ineludible de la prisión donde domina la geometría del muro, la frialdad de la piedra y la oscuridad casi total.

Lena Constante se iniciará también en la creación de versos entre las sesiones de declaración de las encuestas a las que era sometida. Imaginaba bosques, caminos, montañas o ciudades y se concentraba en las cuestiones técnicas de la selección cuidadosa de las palabras, de las sonoridades y de su composición. Por la noche antes de dormir repetía cada pieza poética. Después imaginará cuentos para niños. A estos cuentos añade sencillas creaciones manuales con material a su alcance, hebras de tejido y pequeñas briznas de madera y de otros materiales. Todo ello constituía su evasión. Igualmente, de modo circunstancial pudo tener un cuaderno y colores para ilustrar los cuentos y poner en escena a animales. Esta actividad, en la que se siente a gusto debido a su vinculación anterior con las artes plásticas y la escenografía teatral, le reporta alegría frente a la situación de malestar (Constante, 1990: 86).

Constante, tras la experiencia que adquiere en mantener viva la creatividad, explora otra experiencia literaria: la creación de una obra de teatro en prosa con dos personajes que se enfrentan a dos concepciones de la vida muy diferentes. Construye el marco, establece las pinceladas iniciales de los personajes y después deja que evolucionen en la trama con rasgos cómicos. Se concentra en la rima y finalmente se olvida, una vez más, de la realidad en la que vive (Constante, 1990: 96). Observa, entonces, que su arte de creación adquiere una dimensión catártica.

Su siguiente proyecto será también la creación de una obra de teatro, en la encrucijada de un cuento de hadas. Su personaje principal es una princesa triste que no conoce la alegría y que desde muy temprana edad está familiarizada con la tristeza debido a la pérdida de sus padres. La vida le irá enseñando a recuperar la alegría y a crear dentro de ella la fortaleza necesaria para sonreír. Desarrolla 35 papeles diferentes y avanza lentamente, cada día perfila las palabras y sus sonoridades con el objetivo de encajar los versos en el conjunto (Constante, 1990: 102). 
Con su llegada a la cuarta prisión, su verdugo le regala un cuaderno, un lápiz, una goma, un pincel y acuarelas. Todos los días dedicaba 15 horas de trabajo, que le permitieron realizar varios cuentos en verso con ilustraciones. Las historias, donde vuelven a predominar los animales, tenían siempre elementos alegres que hacían posible la evasión ante la extrema dureza de las condiciones materiales: "Dans cette invisible carapace je sauvegardais le peu qui me restait de liberté. De liberté spirituelle. Tout fil rompu, toute ouverture menaçait ce fragile équilibre intérieur" (Constante, 1990: 112). Por otra parte, con su llegada a la cárcel de Dumbraveni, después del proceso, pesa sobre ella una dura condena y busca su evasión en el hecho de reflexionar sobre la creación de una nueva obra de teatro: "Les jours sont interminables. Je cherche un sujet de pièce de théâtre. Que faire? À quoi penser? Comment vivre?" (Constante, 1990: 180). Y más adelante el trabajo de versificación le permite vivir cierta tranquilidad interior (Constante, 1990: 184). Poco a poco la obra de teatro cobra complejidad en la acción y en los diálogos. Además, Constante introduce elementos cómicos que le hacen alcanzar la evasión desde la ironía, el humor y el escepticismo (Constante, 1990: 215).

En paralelo, mientras la autora trabaja en la creación de la obra de teatro, piensa en la construcción de los temas de dos epigramas relacionados con alguna de sus vivencias. En particular se trata de expresar el hambre de manera irónica, una de las torturas a las que en todo momento se ve sometida en la cárcel:

Dans une gamelle

Une soupe claire.

Dans la soupe claire

Quelques gros pois verts

Et dans chaque pois vert

Un gros petit ver.

Les petits vers blancs

Sont des vers enfants

Mais à la surface

Ceux qui se prélassent

Grands, gros et tout blancs

Sont les vers parents (Constante, 1990: 216-217). 
Su última obra de teatro para marionetas abordó el tema de Ensemble que refleja la relación de amistad con sus vecinas con las que fue capaz de comunicarse a través de los muros. Constante quería hacer el elogio a la amistad en los centros penitenciarios femeninos: "de l'amitié camaraderie à l'amitié intérêt, de l'amitié tendresse à l'amitié passion" (Constante, 1990: 271). Durante todo el tiempo de prisión compone ocho obras de teatro de unos dos mil versos cada una, con posterioridad solo será capaz de recuperar de su memoria tres de ellas y ninguna será publicada. Lena también cultivará el hecho de recordar los sueños y todos sus detalles para poder ensoñar la libertad y la ternura materna (Constante, 1990: 253).

Y por último, tras el ingente trabajo realizado de composición, Constante sabe que no se puede considerar feliz, no puede habituarse a los carceleros, a los dolores morales y carnales, en última instancia a la falta de libertad. Desarrolla otra faceta, la búsqueda de la espiritualidad, y siente una profunda paz de espíritu:

Je me suis mise à penser à Dieu.

J'avais depuis toujours la croyance en l'esprit. En prison, dès le début, cette croyance m'avait soutenue. Je ne pouvais croire que l'homme n'est que matière mesurable. Non. J'étais une parcelle de l'esprit éternel et infini, planant partout, depuis toujours et sans fin et que les hommes nommaient Dieu. Donc, une parcelle aussi infime fût-elle devait, elle aussi, être nécessairement infinie (Constante, 1990: 274-275).

En suma, Constante se configura en un personaje que simboliza la dicotomía y el desequilibrio entre el yo interior, frágil y perseverante, y la instancia exterior, el universo de la cárcel representativo de una configuración social e ideológica dominante en un determinado momento de la Historia. Sin embargo, por encima de los elementos anecdóticos se desarrolla otra fuerza relativa a la búsqueda de un espacio transcendente con capacidad para subvertir las fuerzas materiales. Desde esta perspectiva, la experiencia de Lena en la cárcel nos ofrece una triple dimensión: ontológica, estético-ética e histórico-ideológica. Muestra que el terror es una lacra irreparable.

Por todo ello, el acto de escritura carcelaria de Lena Constante arraiga en el panorama literario contemporáneo como un ejemplo paradigmático de funcionalidad existencial y creativa, gracias al cual el ser 
contemporáneo se crea a sí mismo al margen de la experiencia totalitaria. El nuevo ser ensueña una utopía que sólo la creación verbal y la recreación de mundos imaginarios pueden sacralizar.

\section{Conclusión}

L'évasion silencieuse de Lena Constante ilustra el universo carcelario, silenciado durante años, en el que se percibe la dicotomía interna entre autoridad vs libertad, dos polos en confrontación a lo largo de todo el relato autobiográfico. La autora, sometida a la fuerza del Estado y de sus verdugos, no deja por ello de imaginar otros mundos posibles y crea otra realidad cercana al universo de la creación, la ficción y la ensoñación expresada en una rica variedad estética de dimensiones transgresoras y liberadoras.

Por otra parte, en correlación con la propuesta de Tzvetan Todorov en su último ensayo, Les abus de la mémoire (2015), podemos observar asimismo que la actualización del pasado que lleva a cabo Constante permite ir más allá y nos ofrece la posibilidad de reflexionar sobre el presente y las nuevas circunstancias. Lena Constante no quiere representar una voz aislada sino convertirse en la expresión de toda una colectividad que durante muchos años ha vivido la esclavitud. Se propone instaurar un mundo mejor, liberado de las heridas del pasado.

Y por último, en recuerdo a Lena Constante, exiliada en la lengua francesa para contar su testimonio carcelario en el contexto de la opresión totalitaria, finalizamos con las palabras de Svetlana Aleksiévich, Premio Nobel de Literatura en 2015, de su obra El fin del "Homo sovieticus" (2015):

Así fue el socialismo y ésa la vida que tuvimos. No solíamos hablar de ella antes. Pero ahora que el mundo ha mutado incontrovertiblemente, aquellas vidas nuestras interesan a todos, no importa cómo fueran, eran las vidas que nos tocó vivir. Yo escribo, reúno las briznas, las migas de la historia del socialismo "doméstico", del socialismo "interior"... Estudio el modo en que consiguió habitar en el espíritu de la gente. Siempre me ha atraído ese espacio minúsculo, el espacio que ocupa un solo ser humano, uno solo... Porque, en verdad, es ahí donde ocurre todo (Aleksiévich, 2015: 10). 


\section{Bibliografía}

Aleksiévich, Svetlana. 2015. El fin del "Homo sovieticus". Barcelona: Acantilado. Traducción de Jorge Ferrer.

Alfaro, Margarita. 2012. Oana Orlea. En Mathis-Moser, Ursula \& MertzBaumgartner, Birgit (dir.) Passages et ancrages en France. Dictionnaire des écrivains migrants de langue française (1981-2011). Paris: Honoré Champion, 678-681.

Camboulives, Bernard. 2005. La Roumanie littéraire. Aperçu à l'usage des lecteurs francophones. Paris: Éditions Le Manuscrit.

Cesereanu, Ruxandra. 2005. Gulagul în conştiinţa romănească. Memorialistica şi literatura închisorilor şi lagărelor comuniste. Eseu de mentalitate. Iaşi: Polirom.

Constante, Lena. 1990. L'évasion silencieuse. Trois mille jours seule dans les prisons roumaines. Paris: Éditions La Découverte.

Constante, Lena. 1993. Evadarea imposibilă, București: Editura Florile Dalbe.

Constante, Lena. 1995. Evadarea tăcută. 3000 de zile singură în închisirole din România. Bucareşti: Editura Florile Dalbe.

Delbart, Anne Rosine. 2005. Les exilés du langage. Un siècle d'écrivains français venus d'ailleurs (1919-2000). Limoges: PULIM, Collection Francophonies.

Geambei, Ileana-Lavinia. 2013. Le refuge dans l'imaginaire dans L'évasion silencieuse. En Alexandrina Mustăţea (dir.) Langue et littérature. Repères identitaires en contexte européen. Piteşti: University of Piteşti Press.

Arendt, Hannah. 1974. Los orígenes del totalitarismo. Madrid: Taurus. Traducción de Guillermo Solana.

Lazăr, Adriana. 2013. La littérature roumaine sous censure. Journal European Landmarks of identity, 12: 171-175.

Orlea, Oana. 1992. Les années volées. Dans le goulag roumain à seize ans. Paris: Éditions du Seuil.

Porra, Véronique. 2011. Langue française, langue d'adoption. Une littérature "invitée" entre création, stratégies et contraintes (1946-2000). Hildesheim/Zürich/New York: Georg Olms Verlag.

Steiciuc, Elena-Brandusa. 2010. La Roumanie des années staliniennes dans les écrits de deux “voix de l'exil". Rodica Iulian et Oana Orlea. Francofonia 58, primavera: $139-147$.

Todorov, Tzvetan. 2015. Les abus de la mémoire. Paris: Arléa. 